\title{
The effects of psychological treatment in primary care in Sweden-A practice-based study
}

\author{
ROLF HOLMQVIST, THOMAS STRÖM, ANNIQA FOLDEMO
}

\begin{abstract}
Holmqvist R, Ström T, Foldemo A. The effects of psychological treatment in primary care in Sweden-A practice-based study. Nord J Psychiatry 2013;64:1-9.

Background: Practice-based studies have found substantial effects of psychological treatment in routine care, often equivalent between treatment methods. Factors that moderate treatment outcome may be important to assess. Aim: The purpose of this study was to evaluate treatment outcome in psychological treatment in primary care, and to compare outcome between the most frequently used methods. An additional aim was to study factors that might moderate outcome differences. Method: The Clinical Outcome in Routine Evaluation (CORE) system was used to evaluate psychological treatment at Swedish primary care centers. Treatment methods were coded by the therapists after treatment. Three major treatment orientations-directive (cognitive, behavioral and CBT), reflective (psychodynamic and relational) and supportive therapy were compared. Patient and therapist variables were studied as treatment moderating factors. Results: Analyses of 733 therapies, delivered by 70 therapists, showed good results in short psychological treatments (median session number $=6$ ). Forty-three percent of the patients were remitted, 34\% recovered. For patients receiving at least five sessions, the figures were $50 \%$ and $40 \%$. Directive therapy and reflective therapy had comparable outcome, and better than supportive treatment. Patients in supportive therapy had higher age and received fewer therapy sessions. The patients' motivation, alliance capacity and reflective ability, as rated by the therapist after treatment, were lower for patients in supportive treatment. Conclusions: Psychological treatment in primary care obtains god results. Supportive therapy should be studied more systematically, particularly with regard to variables that may moderate treatment outcome.

- Patient moderator variables, Practice-based study, Psychological treatment, Supportive therapy, Treatment outcome.
\end{abstract}

Rolf Holmqvist, Department of Behavioral Sciences and Learning, Linköping University, 581 83 Linköping, Sweden, E-mail: Rolf.Holmqvist@liu.se; Accepted 13 April 2013

A lthough randomized and controlled treatment trials are the accepted way to study treatment effects, they have a number of drawbacks that have promoted naturalistic studies as alternative ways to gain knowledge about effects of psychological treatments $(1,2)$. In randomized clinical trials (RCT), therapists are specifically trained and supervised in the treatment method. This kind of competence and support usually does not exist in routine care. Recovery from a circumscribed symptom or problem is usually the aim in RCT trials, whereas patients in routine treatment often have multiple and combined problems, and problem patterns may change during treatment. In RCTs, adherence monitoring prescribes and proscribes interventions, whereas therapists in routine care usually use the breadth of their clinical competence in treatment delivery in order to tailor the treatment for the individual patient.

Comparisons between the treatment effects in RCT studies and studies of therapies delivered as routine treatment have given varying results $(3,4)$. Given the fact that therapists do not have specific training and patients are not selected on restrictive criteria, naturalistic studies seem to have surprisingly good effects (5-8). Minami et al. (9) for instance, in a research overview found virtually no differences between depressed patients in ordinary managed care and results from clinical trials. The effect sizes for routine treatment ranged from $d=0.80$ to $d=1.12$. In a large practice-based study in primary care 
in England, Stiles et al. (5) found the overall effect size to be $d=1.39$. A comparison between three treatment orientations - cognitive behavior therapy (CBT), psychodynamic therapy (PDT) and person-centered therapy (PCT) showed no differences. The diversity in patient problems, therapist training and treatments delivered is the precondition for studies of treatments in routine care. Such studies do not answer questions about optimal effects in optimal conditions. They indicate what results may be attained in ordinary treatment (10).

In this study, special interest was directed to supportive therapy. Supportive therapy is somewhat of a Cinderella in psychological treatment. Although frequently used (11), it has seldom been studied in its own right (12). Most studies of supportive therapy have used it as a common-factor treatment to be compared with a supposedly more effective treatment $(13,14)$. A recent meta-analysis indicated that supportive treatment for depression may have similar effects as more systematic therapies when researcher allegiance is controlled for (15). A common clinical view is that patients should receive treatment according to their ability to make use of the method, and this is supported by research overviews (16). This might be particularly important when therapists decide to use supportive therapy, as this therapy is often recommended for patients who are less motivated for more challenging therapies. No studies, however, have been made of patient factors that might influence or moderate the effects of supportive therapy.

The aim in this study was to assess treatment outcome in psychological treatment in primary care and to study outcome differences between treatment orientations. A third aim was to study patient and therapist variables that might influence or moderate outcome.

\section{Method \\ Participants}

\section{PATIENTS}

Over 6 months (November 2009 through April 2010), all patients who were referred for psychological treatment to a social worker, psychologist or psychotherapist at primary care centers in two Swedish regions (Östergötland and Jönköping) were asked to participate in the study. The number of potential patients and attrition at different levels are presented in Fig. 1.

The main reasons for not participating at all were that the participants found the procedure too stressful or burdensome, or that the therapists regarded the patient as not being able to participate, e.g. because of age, acute distress or language problems.

In all, 5085 Clinical Outcome in Routine EvaluationOutcome Measure (CORE-OM) questionnaires were returned. They were completed by 1107 patients, seen by 83 therapists. From 253 patients, only one questionnaire was received. There were 854 patients, treated by 73 therapists, who had participated in at least two therapy sessions. Among those, 121 patients scored below the cut-off score for clinical significance at the first session and were excluded for this reason from the analyses in this paper. In the main outcome analyses, data from these patients is used. From 199 patients, there were no Endof-therapy forms and thus treatment orientation was not known. For another 108 patients, several treatment methods were ticked. Thus, in comparisons of outcome for distinct methods, data from these patients was used.

The patients were referred by their general practitioner at the health care service, or in some cases, were self-referred. The psychological treatment is an adjunct treatment available for those patients whom the medical doctors evaluate as being in need of more or other treatment than the medication that the doctor may prescribe. About one third of the patients had psychotropic medication. There were $76 \%$ women among the patients; the mean age was 37.3 (standard deviation, $s=14.3$, median 35).

\section{THERAPISTS}

The 70 therapists were social workers $(n=42)$, psychologists $(n=22)$, psychiatric nurses or occupational therapists. They had on the average 10 years of experience working with psychotherapy. Sixty-five therapists had a basic training in psychotherapy (in addition to the training included in their basic education) and 21 had advanced training, implying certification as psychotherapist. The proportions of therapists with basic and advanced psychotherapy training did not differ between social workers and psychologists. Thirty-five therapists had training in PDT, 29 in cognitive therapy and 20 in CBT or behavior therapy. Training in different methods was evenly distributed between social workers and psychologists, and many therapists had training in several methods.

\section{Treatments}

The treatments were delivered at primary care units. They were usually of quite short duration. At the Endof-therapy form, the therapists ticked one or more of 14 different therapy orientations: psychodynamic, cognitive, behavioral, CBT, time-limited, existential, relational, patient-centered, systemic, supportive, expressive, interpersonal, crisis intervention and counseling. Therapists could tick several methods for the same treatment. No control was made for treatment integrity.

In this study, comparisons between methods were limited to those treatments where only one method was used. But as most combined treatments used related methods, such as cognitive therapy and CBT, two overarching method groups were created in order not to 


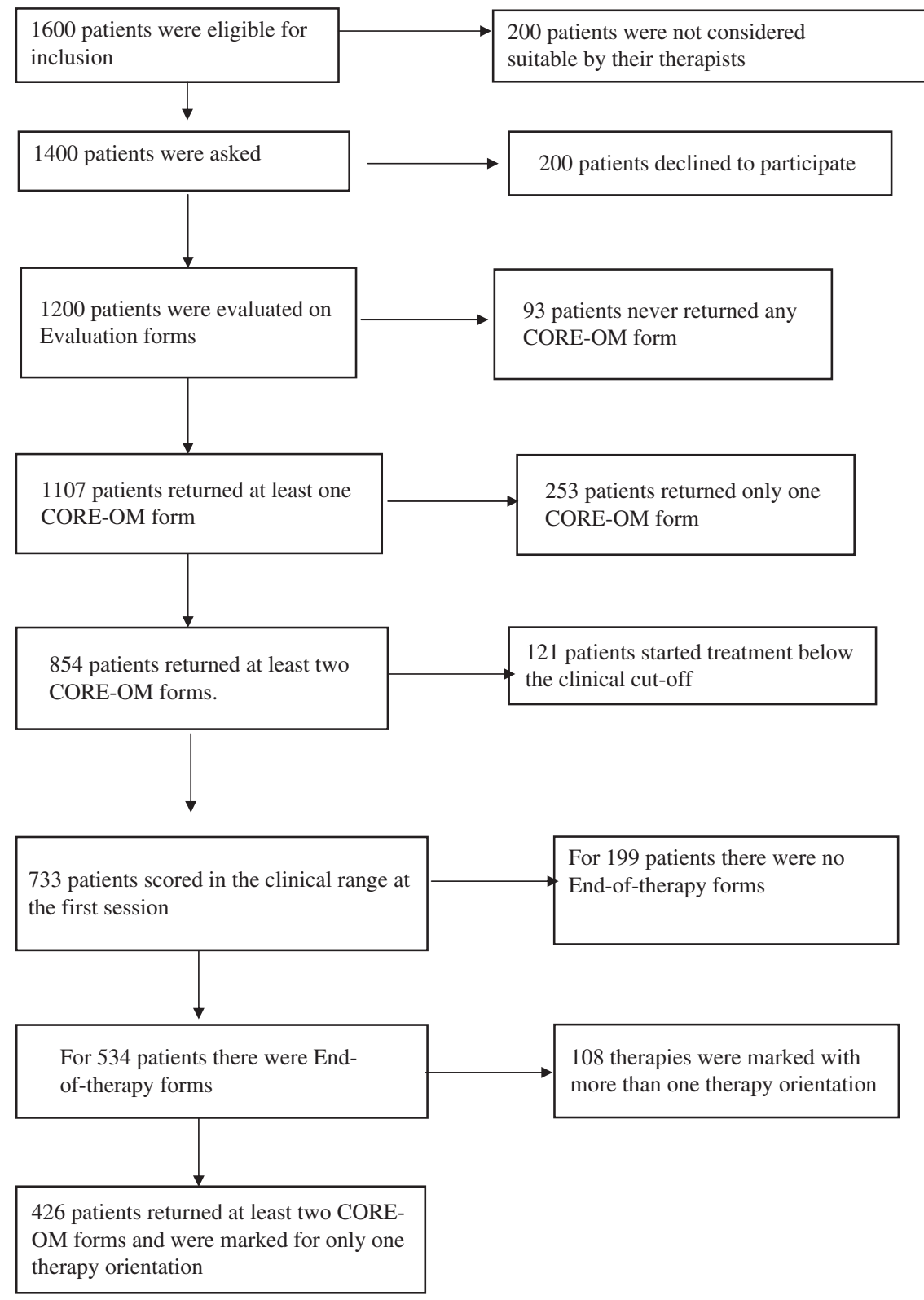

Fig. 1. Flowchart of patient attrition and missing data.

lose data. Therapies that were marked as psychodynamic and/or relational were grouped into reflective therapy, and those that were marked as cognitive, behavioral and/or CBT were combined to a group called directive therapy.

Twenty therapies were ticked as both dynamic and relational, 21 therapies were ticked as behavioral and cognitive, six were ticked as cognitive and CBT, five as behavioral and CBT. There were 85 therapies that were ticked as directive, reflective or supportive, or all three.

At most primary care units, there are one or possibly two therapists. Thus, assignment was in most cases made to the therapist and not to a treatment method. In other words, assignment to a therapist implied that the patient was treated with one of the methods that this particular therapist mastered.

\section{Instruments}

The study was based on the Clinical Outcome in Routine Evaluation (CORE) system $(17,18)$. This system was developed in order to study effects of psychological treatment in primary care $(18,19)$ and has later been found to be adequate also for treatment evaluation in psychiatric treatment. Before each therapy session, the patient completed the CORE-OM (Clinical Outcome in Routine Evaluation-Outcome Measure) form. It consists of 34 items measuring psychological distress on a 5-point scale ranging from "Not at all" to "Most or all the time". The 
scoring is problem-oriented in that higher scores indicate more distress. The instrument has shown good internal and test-retest reliability (0.75-0.95), convergent and discriminant validity, and sensitivity to change $(19,20)$. Based on the first CORE-OM questionnaire from each patient, the internal consistency in this study was found to be $\alpha=0.79(n=1098)$ for the whole scale.

The CORE-OM ratings can be summed up to several subscales. In this study, the depression subscale (four items), the anxiety subscale (four items), the overarching Function subscale (12 items) and (Problems) Symptom subscale (12 items including depression and anxiety) were used, in addition to the total scale. The sum score may range from 0 to 40 .

\section{Therapist ratings}

The therapists completed the CORE Assessment form (19) when the therapies started and the CORE Endof-therapy form when the therapy terminated.

On the Assessment form, the therapists give information about the reasons for referral, about the patient's demographics, and about the nature, severity and duration of the problems.

On the End-of-therapy questionnaire, the therapist ticks on a list with 14 alternatives on which therapy or therapies were used. The therapist also rates three aspects of the patient's work in therapy on a three-grade scale: motivation, reflective ability and alliance.

\section{Procedure}

Patients who were referred for psychological treatment at the primary care centers were asked to participate. If the patient agreed to participate, he or she received an envelope containing the CORE-OM to be completed after the session. Next time, the patient received the envelope with the questionnaires at the reception desk before the session. The patient completed the CORE-OM in the waiting room, before the session and delivered in a closed envelope. At most centers, there was only one counselor, which limited the choice of therapy orientations that could be used. All questionnaire completion was made with paper and pencil.

\section{Data analysis}

Improvement was assessed as gain scores, standardized residuals, within-group effect sizes (Cohen's $d$ ), remitted and recovered patients. Remitted was defined as having attained a reliable change (21). Based on test-retest reliability in a non-clinical Swedish sample (Spearman's rho $=0.85(22)$ ), the reliable change index $(\mathrm{RCI})$ was set to 6.3 points. In order to decide the cut-off between the clinical and non-clinical ranges, criterion (c) in Jacobson \& Truax (21) was used, a criterion that has also been used in previous CORE studies:

$$
\frac{\text { Mean }_{\text {clin }} S_{\text {norm }}+\text { mean }_{\text {norm }} S_{\text {clin }}}{S_{\text {norm }}+S_{\text {clin }}}
$$

Using the clinical scores in this study and the nonclinical scores (mean $=9.0, s=5.2)$ in (22), the cut-off value was found to be 13.03 (abbreviated to 13). This figure could be compared with the figures in Barkham et al. (3). In that study of primary care patients in England, the clinical cut-off was 11.9 for men and 12.9 for women, and the reliable change index 4.8 .

Thus, in the present study individuals were defined as recovered if they left therapy with a CORE score that had improved by at least 6.3 points, if they scored over 13 when they started therapy and below 13 as end score. Patients who improved by 6.3 points but who did not come under 13 at the end, or improved by 6.3 points but started treatment below 13 were considered as remitted and those who worsened by at least 6.3 points were regarded as deteriorated if they left treatment in the dysfunctional range.

The average number of sessions for the patients who came for more than one session was $6.8(s=4.6)$ with a median of 6 and a mode of 4 . The range was from 2 to 35. As most therapy orientations presuppose that therapies should have a certain length, it might seem inappropriate to compare treatments designated as for instance CBT or psychodynamic that lasted for only a few sessions. In order to adjust for this, separate analyses were made for therapies including all cases (also with short duration) and those that contained at least five sessions. The average number of sessions in the group of therapies with at least five sessions $(n=347)$ was $9.3(s=4.6$; median 8 , mode 6). Data were analyzed with $t$-tests, analyses of variance (ANOVAs) and covariance (ANCOVAs).

The study has received research ethical consent from the Ethic Approval Committee at Linköping University (M72-09). All patients and therapists were properly informed about the study, gave their informed consent and were told that they would receive the same treatment if they chose not to participate.

\section{Results}

\section{Treatment outcome}

Outcome analyses were only made for those patients $(n=733)$ who initially scored over the cut-off limit for clinical significance, i.e. 13.0, on the total scale. Initial scores, final scores on the whole CORE-OM scale and the subscales used in this study, and the significance of the differences between initial and final scores are presented in Table 1.

The results in Table 1 imply that there large and highly significant differences between initial and final scores on all scales, although the difference was somewhat smaller on the Function subscale. 
Table 1. Initial and final scores on the total Clinical Outcome in Routine Evaluation-Outcome Measure (CORE-OM) scale and on the depression, anxiety, function and symptoms subscales, the significance of the difference between them and the effects size $(n=667)$.

\begin{tabular}{lccccc}
\hline Scale & $\begin{array}{c}\text { Initial } \\
\text { score }\end{array}$ & $\begin{array}{c}\text { Final } \\
\text { score }\end{array}$ & $T$ & $P$ & Cohen's $d$ \\
\hline CORE-OM total & $19.3(4.1)$ & $13.7(6.1)$ & 387.3 & $<0.001$ & 1.37 \\
Depression & $26.6(6.3)$ & $18.2(9.0)$ & 292.5 & $<0.001$ & 1.35 \\
Anxiety & $25.0(6.6)$ & $17.0(8.7)$ & 282.8 & $<0.001$ & 1.21 \\
Function & $18.2(5.0)$ & $13.4(6.4)$ & 169.0 & $<0.001$ & 0.94 \\
Symptoms & $25.6(5.4)$ & $18.4(8.0)$ & 270.5 & $<0.001$ & 1.33 \\
\hline
\end{tabular}

Out of the 733 patients, 315 patients (43\%) were remitted (CORE-OM score decreased more than 6.3 points) and 249 (34\%) were recovered. Among the 376 patients who had received at least five sessions, 188 patients $(50 \%)$ were remitted, and 150 patients $(40 \%)$ were recovered. Four patients $(0.6 \%)$ were deteriorated.

\section{Outcome in relation to orientation}

The therapists could tick more than one orientation for each therapy. The most common orientations among the 534 therapies that were marked for therapy orientation were, when combinations were included, supportive (29\%), psychodynamic (24\%), CBT (18\%), cognitive (15\%) and crisis intervention (15\%); 332 (65\%) therapies had been ticked with only one orientation, $128(25 \%)$ with two orientations, $38(7 \%)$ with three orientations and $15(3 \%)$ with four orientations.

In Table 2, outcomes for the different therapy directions are presented for those therapies that were ticked for only one therapy orientation. In addition to the results for discrete therapies, results for reflective and directive therapies are also described. There were 173 directive therapies and 99 reflective therapies, when combinations with other orientations were not included. Gain scores and effect sizes are presented for those orientations where at least 10 therapies were delivered.

The differences on CORE-OM outcome for the different discrete orientations were assessed with covariance analyses, where the scores at treatment start were entered as covariates. The differences between the discrete treatment orientations were significant $(F(6,309)=3.68$, $P=0.002)$. For Function, the differences were also significant $(F(6,309)=2.22, P=0.04)$ and for Symptoms, $F(6,309)=3.72, P=0.001$.

The differences in outcome between directive and reflective therapy were not significant. For CORE-OM, the covariance analysis gave $t(1,199)=0.96, P=0.33$ for the whole scale, for Function $t(1,199)=1.11, P=0.30$, and for Symptoms, $t(1,199)=0.92, P=0.34$.

Table 3 shows the results for therapy orientations when only therapies that lasted more than five sessions were used in the analyses. Figures are presented only for those methods where at least 10 therapies were performed.

In the comparison between therapies with at least five sessions presented in Table 3, the differences in outcome for the discrete methods were significant when initial scores were entered as covariates. For COREOM, the ANCOVA gave $(F(5,183)=4.57, P=0.001)$, for Function $(F(5,183)=2.49, P=0.03)$ and Symptoms $(F(5,183)=4.73, P<0.001)$.

The differences between directive and reflective therapies were not significant. For CORE-OM, the analysis gave $t(1,151)=0.44, P=51$, for Function $t(1,151)$ was $0.42, P=0.52$, and for the Symptom scale, $t(1,151)=$ $0.69, P=0.41$.

\section{Differences between directive, reflective and supportive therapies}

As supportive therapy was found to be the most frequently used therapy form, at least when combinations were allowed, a special analysis was made of the differences

Table 2. Mean initial and final scores for therapy orientations with more than 10 therapies, standard deviations, gain scores and effect sizes (ES) $(n=309)$.

\begin{tabular}{|c|c|c|c|c|c|c|c|c|c|c|c|c|c|}
\hline & \multicolumn{5}{|c|}{ Whole CORE-OM } & \multicolumn{4}{|c|}{ Function } & \multicolumn{4}{|c|}{ Symptoms } \\
\hline & Pre & Post & $\begin{array}{l}\text { Gain } \\
\text { score }\end{array}$ & ES & Pre & Post & $\begin{array}{l}\text { Gain } \\
\text { score }\end{array}$ & ES & Pre & Post & $\begin{array}{l}\text { Gain } \\
\text { score }\end{array}$ & ES & $n$ \\
\hline Supportive & $19.7(4.5)$ & $15.3(5.9)$ & $4.5(5.3)$ & 1.00 & $18.9(5.2)$ & $14.9(6.6)$ & $4.0(5.8)$ & 0.77 & $26.0(5.7)$ & 20.4 (7.6) & $5.6(7.2)$ & 0.98 & 86 \\
\hline Dynamic & $19.2(4.0)$ & $12.5(5.3)$ & $6.7(5.4)$ & 1.68 & $18.4(4.8)$ & $12.7(6.1)$ & $5.7(5.8)$ & 1.19 & $24.9(5.6)$ & $16.6(7.1)$ & $8.3(7.4)$ & 1.48 & 69 \\
\hline CBT & $19.6(3.6)$ & $12.0(5.4)$ & $7.6(5.4)$ & 2.11 & $18.4(4.2)$ & $12.7(5.8)$ & $6.3(5.7)$ & 1.50 & $25.2(4.8)$ & $15.6(7.0)$ & $9.6(7.4)$ & 2.00 & 73 \\
\hline Cognitive & $20.0(4.1)$ & $11.3(5.6)$ & $8.7(5.6)$ & 2.12 & $18.9(4.5)$ & $11.4(6.0)$ & $7.6(5.7)$ & 1.69 & $26.4(5.1)$ & $15.4(7.4)$ & $11.0(8.1)$ & 2.16 & 37 \\
\hline Crisis intervention & $19.2(4.4)$ & $12.9(6.6)$ & $6.3(6.6)$ & 1.43 & $17.3(4.9)$ & $12.2(6.8)$ & $5.2(6.8)$ & 1.06 & $26.0(6.4)$ & $17.5(8.8)$ & $8.5(8.5)$ & 1.33 & 30 \\
\hline Behavioral & $19.1(3.7)$ & $13.8(6.0)$ & $5.3(4.1)$ & 1.43 & $18.0(5.3)$ & $13.1(6.7)$ & $4.8(4.4)$ & .91 & $24.9(5.0)$ & $18.4(8.4)$ & $6.6(6.6)$ & 1.32 & 16 \\
\hline Systemic & $19.1(4.9)$ & $11.9(5.6)$ & $7.2(8.6)$ & 1.47 & $19.6(6.8)$ & $12.9(6.0)$ & $6.7(10.0)$ & .99 & $22.6(4.6)$ & $14.5(7.5)$ & $8.1(8.7)$ & 1.76 & 11 \\
\hline Directive & $19.6(3.7)$ & $12.0(5.5)$ & $7.6(5.4)$ & 1.84 & $18.6(5.3)$ & $12.9(6.4)$ & $5.6(5.9)$ & 1.06 & $25.5(4.9)$ & $15.9(7.3)$ & $9.6(7.6)$ & 1.96 & 125 \\
\hline Reflective & $19.4(4.4)$ & $12.6(6.0)$ & $6.8(5.8)$ & 1.55 & $18.6(5.3)$ & $12.9(6.4)$ & $5.6(5.9)$ & 1.06 & $25.2(5.8)$ & $16.7(7.3)$ & $8.4(7.5)$ & 1.45 & 77 \\
\hline
\end{tabular}

CORE-OM, Clinical Outcome in Routine Evaluation-Outcome Measure; CBT, cognitive behavior therapy. 
Table 3. Results of therapies with at least five sessions. Initial and final scores for therapy orientations, gain scores and effect sizes (ES).

\begin{tabular}{|c|c|c|c|c|c|c|c|c|c|c|c|c|c|}
\hline & \multicolumn{5}{|c|}{ Whole CORE-OM } & \multicolumn{4}{|c|}{ Function } & \multicolumn{4}{|c|}{ Symptoms } \\
\hline & Pre & Post & $\begin{array}{l}\text { Gain } \\
\text { score }\end{array}$ & ES & Pre & Post & $\begin{array}{l}\text { Gain } \\
\text { score }\end{array}$ & ES & Pre & Post & $\begin{array}{l}\text { Gain } \\
\text { score }\end{array}$ & ES & $N$ \\
\hline Supportive & $20.4(4.5)$ & $16.4(6.1)$ & $4.0(4.3)$ & 0.89 & $19.3(5.2)$ & $15.6(6.4)$ & $3.7(4.7)$ & 0.71 & $26.8(5.1)$ & $22.1(7.7)$ & $4.7(6.0)$ & 0.92 & 33 \\
\hline Dynamic & $19.6(3.2)$ & $12.2(5.4)$ & $7.3(5.7)$ & 1.78 & $18.2(5.1)$ & $12.3(5.6)$ & $6.9(5.5)$ & 1.16 & $25.6(5.1)$ & $16.4(6.6)$ & $9.1(7.5)$ & 1.78 & 49 \\
\hline CBT & $19.6(5.7)$ & $11.3(4.7)$ & $8.2(5.1)$ & 2.28 & $18.6(4.1)$ & $11.7(5.2)$ & $7.0(5.8)$ & 1.71 & $25.3(4.7)$ & $14.8(6.5)$ & $10.5(7.3)$ & 2.23 & 57 \\
\hline Cognitive & $20.3(5.0)$ & $12.5(6.2)$ & $7.8(6.5)$ & 1.56 & $19.0(5.1)$ & $12.2(5.9)$ & $6.9(6.3)$ & 1.35 & $26.2(5.4)$ & $16.4(7.9)$ & $9.8(8.0)$ & 1.81 & 15 \\
\hline Directive & $19.9(3.5)$ & $11.7(5.4)$ & $8.2(5.3)$ & 2.34 & $19.0(4.2)$ & $12.1(5.8)$ & $7.0(5.6)$ & 1.67 & $25.7(5.0)$ & $15.2(7.3)$ & $10.5(7.7)$ & 2.10 & 96 \\
\hline Reflective & $19.8(4.4)$ & $12.3(5.8)$ & $7.5(5.9)$ & 1.71 & $18.6(5.3)$ & $12.6(5.9)$ & $6.0(6.0)$ & 1.13 & $25.9(5.2)$ & $16.4(7.1)$ & $9.5(7.6)$ & 1.83 & 55 \\
\hline
\end{tabular}

CORE-OM, Clinical Outcome in Routine Evaluation-Outcome Measure; CBT, cognitive behavior therapy.

between reflective, directive and supportive therapies. In Table 4, results of comparisons (ANCOVA) between directive, reflective and supportive therapy are shown for the Depression, Anxiety, Function and Symptom subscales and for the whole CORE-OM.

The results in Table 4 show that there were significant differences between the therapy methods. Contrasting the results for supportive therapy with results for reflective and directive therapy for the CORE-OM, significant pairwise differences were found. The contrast estimate was for reflective therapy $0.299(P<0.001)$ and for directive therapy $0.334(P<0.001)$. The $95 \%$ confidence interval for the whole scale, using the Bonferroni correction, was for reflective therapy was $11.1-13.4$, for directive therapy 8.9-12.3 and for supportive therapy 14.2-16.5.

\section{Moderating and co-varying patient factors}

\section{PATIENT AGE AND SESSION LENGTH}

The differences in age for the patients in the three methods (reflective therapy mean age 35.5, $s=13.1$, directive therapy $34.0, s=13.0$ and supportive therapy $38.9, s=15.3)$ approached significance $F(2,260)=2.84$, $P=0.06$ ). Entering age as covariate in the ANCOVA did not change the significance in differences between the methods. The number of sessions also differed significantly between the methods (reflective therapy $=8.4$
(5.4), directive therapy $=7.7$ (3.8), supportive therapy $=4.8(2.6)$ ). Using number of sessions as covariate did not change the significance in differences between the methods.

\section{MotivATION, REFLECTIVE ABILITY, ALLIANCE}

The therapists rated their patients' motivation, reflective ability and alliance after the therapy on the End-of-therapy forms. There were significant differences between the methods concerning these factors. Table 5 shows the scores.

Table 5 shows that there were great differences between the therapy orientations with regard to how the therapists judged motivation, alliance and reflective ability. The patients who received directive and reflective therapies had higher scores on these process ratings than patients who received supportive therapy. The differences between directive and reflective therapies were not significant.

As motivation, reflective ability and alliance ability were rated by the therapists at the End-of-therapy form, they cannot be considered moderating or mediating variables. They should rather be seen as indications of the therapists' evaluation of the treatment process after it was finished. Covariance analyses indicated that when motivation, alliance and reflective ability were entered as covariates in the analyses also using initial CORE-OM

Table 4. Mean gain scores, standard deviations and effect sizes (Cohen's $d$; ES) for reflective, directive and supportive therapies, when they were not combined with other orientations.

\begin{tabular}{|c|c|c|c|c|c|c|c|c|}
\hline & \multicolumn{2}{|c|}{ Reflective $(n=95)$} & \multicolumn{2}{|c|}{ Directive $(n=131)$} & \multicolumn{2}{|c|}{ Supportive $(n=88)$} & \multirow[b]{2}{*}{$F$} & \multirow[b]{2}{*}{$P$} \\
\hline & Gain score & ES & Gain score & ES & Gain score & ES & & \\
\hline Depressive symptoms & $10.6(9.1)$ & 1.69 & $11.4(8.4)$ & 1.93 & $5.5(8.8)$ & 1.06 & 13.2 & $<0.001$ \\
\hline Anxiety symptoms & $9.4(9.1)$ & 1.39 & $10.9(7.7)$ & 1.71 & $5.6(8.4)$ & 1.06 & 12.3 & $<0.001$ \\
\hline Function & $6.0(6.3)$ & 1.13 & $6.6(5.6)$ & 1.43 & $3.9(5.8)$ & 0.75 & 7.3 & $=0.001$ \\
\hline Symptoms & $8.8(8.1)$ & 1.60 & $9.6(7.5)$ & 1.96 & $5.2(7.3)$ & 0.93 & 12.4 & $<0.001$ \\
\hline Whole CORE & $7.2(6.1)$ & 1.67 & $7.7(5.3)$ & 2.03 & $4.3(5.4)$ & 0.98 & 12.7 & $<0.001$ \\
\hline
\end{tabular}

$F$-values and significance of differences between the methods, assessed with ANCOVA analyses.

CORE, Clinical Outcome in Routine Evaluation. 
Table 5. Therapists' ratings of patients' motivation, alliance ability and reflective ability on the End-of-treatment questionnaires for reflective, directive and supportive therapy.

\begin{tabular}{lcccccc}
\hline & $\begin{array}{c}\text { Reflective } \\
(n=93)\end{array}$ & $\begin{array}{c}\text { Directive } \\
(n=130)\end{array}$ & $\begin{array}{c}\text { Supportive } \\
(n=84)\end{array}$ & $F$ & $P$ \\
\hline Motivation & $2.61(0.63)$ & $2.72(0.50)$ & $2.32(0.68)$ & 12.0 & $<0.001$ \\
Alliance & $2.67(0.54)$ & $2.75(0.50)$ & $2.24(0.81)$ & 19.0 & $<0.001$ \\
Reflective ability & $2.43(0.74):$ & $2.63(0.60):$ & $2.12(0.74)$ & 14.2 & $<0.001$ \\
\hline
\end{tabular}

$F$-values and significance of differences between these patient characteristics in the three methods (ANOVA)

rating as covariate, the differences between treatment forms were retained.

In order to estimate the importance of these different variables for outcome, a step-wise linear regression analysis where CORE-OM at treatment end was regressed on CORE-OM at treatment start, number of sessions, patient age, treatment orientation (reflective, directive, supportive, as dummy variables), therapist evaluation of motivation, alliance quality and reflection ability. Table 6 shows the result of this analysis.

The results in Table 6 show that four variables were retained in a step-wise multiple regression analysis: initial CORE-OM score, therapist-rated motivation, supportive therapy and therapist-rated reflective ability accounted for $27 \%$ of the variance in outcome scores. Higher initial symptom score, lower motivation, more supportive therapy and lower reflective ability predicted higher final CORE-OM score.

\section{Therapist moderating factors}

Some significant differences were found between the therapists who gave the different therapies. Thus, an ANOVA and post hoc least significant difference (LSD) analysis showed that therapists giving reflective therapy were significantly older than therapists giving directive and supportive therapy (53.1 vs. 47.1 and $47.7 ; F=19.1$, $P<0.001)$. There was no significant difference in basic education for the therapists giving the three methods, but

Table 6. Variables retained in a step-wise multiple regression analysis with final Clinical Outcome in Routine EvaluationOutcome Measure (CORE-OM) regressed on a number of variables measuring patient and process characteristics.

\begin{tabular}{lccc}
\hline Retained variables & $\begin{array}{c}\text { Standardized Beta } \\
\text { and significance }\end{array}$ & $\begin{array}{c}\text { Model } F \text { and } \\
\text { significance }\end{array}$ & Adjusted $R^{2}$ \\
\hline $\begin{array}{l}\text { Initial score on } \\
\quad \text { CORE-OM }\end{array}$ & $0.36(<0.001)$ & $54.8(<0.001)$ & 0.15 \\
$\begin{array}{l}\text { Motivation } \\
\text { Supportive therapy }\end{array}$ & $-0.18(<0.001)$ & $47.9(<0.001)$ & 0.24 \\
Reflective ability & $-0.13(0.003)$ & $36.5(<0.001)$ & 0.26 \\
\hline
\end{tabular}

Significance of models and beta coefficients, and adjusted $R^{2}$ for the successive models. there were fewer therapists giving supportive therapy who had basic training in psychotherapy than those giving directive and reflective therapy $\left(\chi^{2}=55.6, P<0.001\right)$. There were significantly more therapists with advanced training in psychotherapy who gave reflective therapy than directive and supportive therapy $\left(\chi^{2}=41.2, P<0.001\right)$. Therapists with psychodynamic or cognitive training did not give more or less supportive treatment than expected by their numbers, but therapists with CBT training gave more supportive treatment than expected $\left(\chi^{2}=19.2, P<0.001\right)$.

\section{Discussion}

The results in this study show that routine psychological treatment in primary care is helpful for a large number of patients. A considerable number of the patients were remitted after a very modest number of sessions. The effect sizes, particularly for symptom change, were substantial. There were some differences in effect between treatment orientations: directive and reflective therapies had better results than supportive therapy, even after control for a number of potentially moderating factors, such as patient age and number of sessions.

Naturalistic studies entail several problems. A main problem in this study was that there was no control of the treatment integrity. Treatment orientation was reported but no check of the adherence or competence in delivering the therapies was made. What is reported in this study are results of treatments as they were delivered in routine treatment contexts, with the designations given by the therapists. On the positive side, these treatments are what most patients in fact get, for better or worse, when they are offered a specific treatment type. The results thus have considerable external validity.

Another major problem is the large drop-out of patients and attrition of data. Of 1600 potential participants, analyses of outcome for distinct methods could be made for only 309 patients. There are two distinct aspects of this problem. In naturalistic studies, the challenge to motivate patients and therapists to participate and to deliver data is common (5). The data collection experiences made in this study are now being used in an ongoing similar study at psychiatric clinics. Quite another aspect of the study is the fact that some patients only come for one therapy session, that some patients are treated with a combination of methods, that other treatment methods, like medicine are also used, and that we cannot exclude other factors, like spontaneous remission, as curative. This is in the nature of practice-based data collection, that there are a number of factors that influence the results. The challenge is to include this variation in order to understand it. Thus, for instance, it is an important question for coming analyses to understand why some patients come for only one session. 
No analysis was made of symptom change for patients who only met medical doctors in primary care. We have no possibility of knowing whether the results reflect the effects of good medical primary care, including understanding and empathic talks with doctors. One third of the patients took medication for psychiatric problems. As this medication often had started before the psychotherapy, and we had no control of duration and dose, we cannot know what effect the medical treatment may have had.

Some treatment methods were more effective than others. Cognitive therapy and CBT were more effective than supportive therapy. Several reasons could probably explain this. The most straightforward explanation is that there is a real difference, meaning that some therapy forms give better results, at least in these treatment contexts. But it may also be that those therapy forms that were less successful may have been given by therapists who had less training in these therapies, who were not really very familiar with them, or did not believe in them.

Supportive therapy had less favorable outcome than directive or reflective therapy. Moderating factors such as patient age and number of sessions reduced the difference but did not obliterate it. Major patient differences were found between patients who received these different forms of therapy, e.g. motivation and reflective ability. With the design used in this study, it is not possible to decide whether the rating of some of these factors co-varied with the coding of the therapy form. Thus, these factors cannot be seen as moderating or mediating factors. The results do, however, suggest that patients who get supportive therapy may have reduced potential to benefit from psychological treatments. It is important in future studies to understand to what extent therapists do a deliberate selection of patients for supportive therapy, and whether this treatment may be the most beneficial for certain categories of patients. As there were only few differences between the therapists who delivered supportive therapy in comparison with directive or reflective therapy, one interpretation might be that therapists make a rational choice and give patients with less favorable preconditions for therapy supportive therapy.

It is probable that the therapies that were ticked as supportive therapy represent a diverse array of treatment interventions. Although there exist some guidelines for supportive therapy $(14,23,24)$, therapists in this study may have used the designation in a rather loose way for treatments that were generally confirming and empathic, sometimes with advice or recommendations, but without distinct intervention principles. As the only information about the therapy content is the tick on the orientation list on the End-of-treatment form, we have no information about how the supportive therapies were defined by therapists themselves. Possibly counseling and crisis intervention also could be grouped together with supportive therapy, but we refrained from such combinations in order to not further dilute the content of the therapists' designations.

In clinical reality, therapists have more or less training in several therapy forms, integrated with often many years of experience. Therapy interventions are probably not delivered by the book. They are instead delivered with discretion and common sense, and probably tailored to the individual patient. It is important for future research to study the "ethnography" of psychotherapy practice, mapping the variety of interventions and combinations among them that are found in routine practice. This idea is strengthened by the finding that therapists with CBT training gave somewhat more supportive therapy than therapists without such training. As the primary care does not give room for longer psychological treatments, a possible interpretation is that CBT therapists cannot use their specific methods in this treatment setting and to a somewhat larger extent resort to supportive treatment.

To conclude, the results of this study indicate that psychological treatment in primary care may have a positive influence on the outcome, particularly on symptoms like depression and anxiety. Some outcome differences between methods were found. Among the most frequently used therapy methods, supportive therapy was less successful than directive and reflective therapy. The study gives support to the view that psychotherapy in primary care is effective, even in rather short contacts, and it suggests that therapists' ability to tailor treatment to the specific patient may be important.

Declaration of interest: The authors report no conflicts of interest. The authors alone are responsible for the content and writing of the paper.

\section{References}

1. Barkham M, Mellor-Clark J. Bridging evidence-based practice and practice-based evidence: Developing a rigorous and relevant knowledge for the psychological therapies. Clin Psychol Psychother 2003;10:319-27.

2. Shadish WR, Navarro AM, Matt GE, Phillips G. The effects of psychological therapies under clinically representative conditions A meta-analysis. Psychol Bull 2000;126:512-29.

3. Barkham M, Connell J, Stiles WB, Miles JNV, Margison F, Evans C, et al. Dose-effect relations and responsive regulation of treatment duration: The good enough level. J Consult Clin Psychol 2006;74:160-7.

4. Wampold BE, Budge SL, Laska KM, Del Re AC, Baardseth TP, Flückiger C, et al. Evidence-based treatments for depression and anxiety versus treatment-as-usual: A meta-analysis of direct comparisons. Clin Psychol Rev 2011;31:1304-12.

5. Stiles WB, Barkham M, Mellor-Clark J, Connell J. Effectiveness of cognitive-behavioural, person-centred, and psychodynamic therapies in UK primary-care routine practice: Replication in a larger sample. Psychol Med 2008;38:677-88. 
6. Kraus DR, Castonguay L, Boswell JF, Nordberg SS, Hayes JA. Therapist effectiveness: Implications for accountability and patient Care. Psychother Res 2011;21:267-76.

7. Clark DM, Fairburn CG, Wessely S. Psychological treatment outcomes in routine NHS services: A commentary on Stiles et al. Psychol Med 2008;38:629-34.

8. Stiles WB, Barkham M, Mellor-Clark J, Connell J. Correspondence. Psychol Med 2007;38:905-10.

9. Minami T, Wampold BE, Serlin RC, Hamilton EG, Brown GS, Kircher JC. Benchmarking the effectiveness of psychotherapy treatment for adult depression in a managed care environment: A preliminary study. J Consult Clin Psychol 2008;76:116-24.

10. Lambert M. Presidential address: What we have learned from a decade of research aimed at improving psychotherapy outcome in routine care. Psychother Res 2007;17:1-14.

11. Tanielian TL, Marcus SC, Suarez AP, Pincus HA. Trends in psychiatric practice. 1988-1998, II: Caseload and treatment characteristics. Psychiatr Serv 2001;52:880.

12. Rockland LH. A review of supportive psychotherapy, 1986-1992. Hosp Community Psych 1993;44:1053-60.

13. Budge S, Baardseth TP, Wampold BE, Fl ckiger C. Researcher allegiance and supportive therapy: Pernicious effects on results of randomized clinical trials. Eur J Psychother Counsell 2010;12:23-39.

14. Lipsitz JD, Gur M, Vermes D, Petkova E, Cheng J, Miller N, et al. A randomized trial of interpersonal therapy versus supportive therapy for social anxiety disorder. Depress Anxiety 2008;25:542-53.

15. Cuijpers P, Driessen E, Hollon SD, van Oppen P, Barth J, Andersson G. The efficacy of non-directive supportive therapy for adult depression: A meta-analysis. Clin Psychol Rev 2011;32:280-91.

16. Roth A, Fonagy P. What works for whom? A critical review of psychotherapy research, 2nd edition. New York: Guilford Press; 2005.

17. Evans C, Connell J, Barkham M, Margison F, Mellor-Clark J, McGrath, G, et al. Towards a standardized brief outcome measure: Psychometric properties and utility of the CORE-OM. Br J Psychiatry 2002;180:51-60.

18. Barkham M, Gilbert N, Connell J, Marshall C, Twigg E. Suitability and utility of the CORE-OM and CORE-A for assessing severity of presenting problems in psychological therapy services based in primary and secondary care settings. Br J Psychiatry 2005;186: 239-46.

19. Mellor-Clark J, Barkham M, Connell J, Evans C. Practice-based evidence and need for a standardised evaluation system: Informing the design of the CORE System. Eur J Psychother Counsell Health 1999;3:357-74.

20. Mellor-Clark J, Barkham M. Quality evaluation: Methods, measures and meaning. In: Feltham $\mathrm{C}$ and Horton I, editors. Handbook of counselling and psychotherapy. London: Sage Publications; 2006. p. 207-24.

21. Jacobson NS, Truax P. Clinical significance: A statistical approach to defining meaningful change in psychotherapy research. J Consult Clin Psychol 1991;59:12-19.

22. Elfström M, Evans C, Carlsson S. Validation of the Swedish version of the Clinical Outcomes in Routine Evaluation Outcome Measure (CORE-OM). Clin Psychol Psychother (in press).

23. Pinsker H. A primer of supportive therapy. Hillside, NJ: Analytic Press; 1997.

24. Winston A, Rosenthal R, Pinsker, H. Learning supportive therapy. An illustrated guide. Arlington, VA: APA; 2012.

Rolf Holmqvist, Ph.D., Department of Behavioral Sciences and Learning, Linköping University, Sweden.

Thomas Ström, M.Sc., Department of Behavioral Sciences and Learning, Linköping University, Sweden.

Anniqa Foldemo, Ph.D., Medical and Health Sciences, Linköping University, Sweden. 